Board of Governors of the Federal Reserve System

International Finance Discussion Papers

Number 550

May 1996

\title{
ALTERNATIVES IN HUMAN CAPITAL ACCUMULATION: IMPLICATIONS FOR ECONOMIC GROWTH
}

\author{
Murat F. Iyigun and Ann L. Owen
}

NOTE: International Finance Discussion Papers are preliminary materials circulated to stimulate discussion and critical comment. References in publications to International Finance Discussion Papers (other than an acknowledgment that the writer has had acccess to unpublished material) should be cleared with the author or authors. 


\begin{abstract}
This paper demonstrates that considering alternative means of human capital accumulation, such as learning-by-doing, overturns the presumption that formal education is unconditionally beneficial for economic growth. It analyzes a model in which the average level of human capital creates externalities in future human capital accumulation and individuals can augment their human capital with work experience or education. The model shows that in the early stages of development, education enhances growth by creating a positive externality, and, in later stages, it may depress growth by leading to a negative externality. It also demonstrates the possibility of multiple equilibria in which low-income equilibria are characterized by under-education and high-income equilibria are characterized by over-education.
\end{abstract}




\title{
ALTERNATIVES IN HUMAN CAPITAL ACCUMULATION: IMPLICATIONS FOR ECONOMIC GROWTH
}

\author{
Murat F. Iyigun and Ann L. Owen ${ }^{1}$
}

\section{Introduction}

An overwhelming number of papers on the role of human capital in the growth process conclude that increased levels of human capital lead to either increased growth rates or increased levels of per capita income. Since, in many of these models, more education leads unequivocally to more human capital, the policy implications of this body of work are straightforward.

A topic which has recieved considerably less attention in the growth literature, however, is the complex manner in which individuals increase their human capital and its implications for growth. We take this issue up in this paper, examining how individual decisions to accumulate different types of human capital affect the growth of an economy. By identifying alternative means of accumulating human capital, we are able to show that an economy in the early stages of development may be under-educated but, at a later stage, may become over-educated. In addition, we show the possibility of multiple equilibria in which all equilibria are inefficient-in the low-income equilibria, individuals do not choose enough education, and, in the high-income equilibria they choose too much education. Thus, our model questions the presumption that more education always leads to higher growth and/or higher income and allows us to qualify the policy recommendations of earlier work, showing that the goals of the best educational policy change as an economy grows.

To achieve these ends, we draw on well established ideas regarding the accumula-

\footnotetext{
${ }^{1}$ Murat F. Iyigun is an economist in the Division of International Finance, Board of Governors of the Federal Reserve System and Ann L. Owen is an economist in the Division of Monetary Affairs, Board of Governors of the Federal Reserve System. This paper represents the views of the author and should not be interpreted as reflecting those of the Board of Governors of the Federal Reserve System or other members of its staff. Please send all correspondence to: Division of International Finance, Mail Stop 23, Washington, D.C. 20551. Phone: (202) 452-3798. Fax: (202) 452-6424.
} 
tion of human capital and its effect on growth found in several different strands of the literature. One of the main tenets of this paper is that the skills individuals accumulate through work experience are an important part of human capital. Support for this idea can be found in microeconomic studies of wage determinants [see for example Becker (1993) and Mincer $(1993,1996)]$, and also in macroeconomic examinations of growth through a learning-by-doing process [e.g. Lucas(1993) and Stokey (1988)].

A second element of our model is the role that the existing level of human capital plays in the accumulation of future human capital-the effectiveness of an individual's time spent accumulating human capital increases with the average level of human capital of the previous generation. The importance of the existing level of human capital in generating further human capital has been emphasized in the growth literature [see Lucas (1988), Azariadis and Drazen (1990), Romer (1990) and Galor and Tsiddon (1996) to name a few]. In addition, this specification is also consistent with empirical findings that show that family background plays an important role in educational attainment [See, for example, Coleman (1966)]. However, our definition of human capital that includes specific skills accumulated through work experience as well as improvements to overall mental ability enriches the usual story and allows us to examine the role that education plays in determining the growth and level of per capita income with a slightly different perspective. Thus, in our model, the level of human capital effectively employed in an economy depends on the total skills of the workforce and not just those accumulated by investing in formal education.

Because a key result of our model is that the role of further investment in education changes as an economy develops, in addition to the papers mentioned above, our work is also related to a few recent papers that have begun to question exactly how education affects long-run growth ${ }^{2}$. Benhabib and Spiegel (1994) argue that educated labor is not

\footnotetext{
${ }^{2}$ While several often cited studies [e.g. Barro (1991), Mankiw, Romer, Weil (1992)] that have shown positive correlations between growth rates and school enrollment ratios might seem to suggest that schooling is always better for growth than its alternative, these cross-sectional results are not able to identify the possibility that higher growth could be achieved by a sub-sample of countries if they had a
} 
a factor of production but only affects per capita income through its effect on the level of technology. Fershtman, Murphy and Weiss (1996) investigate conditions under which nonmonetary rewards in the form of occupational status lead to inefficiencies in investment in education and a lower growth rate. Pritchett (1995) goes further in challenging the role education plays in determining per capita income, empirically finding a negative association between the growth of education and total factor productivity. Iyigun and Owen (1995) also explore the role that increases in education play in development in a model in which there are alternative means of accumulating human capital and in which, depending on the stage of development, a parent's level of human capital affects the child's ability to learn through schooling and work experience differently.

In what follows, we consider a three period overlapping generations model. In the first period of life, individuals work and go to school. Both of these activities compete for an individual's time and enhance his skills in different ways. Education increases an individual's general skills (critical thinking and general problem-solving skills) while work experience increases his specific skills (the amount of job-specific skills an individual accumulates through repetition). In the second period, individuals work; and in the third period, they consume.

There is one critical feature of this economy: the way job-specific and general skills are combined in output production is different than the way the two types of skills interact in human capital production. This setup creates a disparity between the socially and individually optimal choices of education. In the early stages of development, increases in the average level of education serve as a positive externality, increasing the average level of human capital and therefore the effectiveness of both education and work experience in accumulating future human capital. This leads to higher levels of human capital and per capita output for given levels of investment in education and work experience. However, because work experience also contributes to specific skills

slightly less educated labor force. In addition, these studies typically focus on primary and secondary enrollment rates levels of schooling for which the negative externality we identify is not likely to exist. 
but competes for time in the first period of life, at later stages of development, increased education "crowds out" investment in specific skills. In this case, further education may act as a negative externality, decreasing the effectiveness of education and work experience in accumulating human capital and, as a result, decreasing per capita income. Therefore, when multiple equilibria exist in this economy, low-income equilibria will be characterized by under-education and high-income equilibria may be characterized by over-education.

Our results are developed in the following four sections: Section 2 describes the basic model, Section 3 discusses its dynamic behavior, Section 4 considers social externalities, and Section 5 concludes.

\section{The Model}

\subsection{Production}

Consider a small open economy that operates in a perfectly competitive world in which economic activity extends over an infinite discrete time. The output of the economy, $Y_{t}$, is a single homogeneous good produced by a CRS production function that uses physical capital, $K_{t}$, raw labor, $L_{t}$, general skills, $G_{t}$, and specific-skills, $S_{t}$, as inputs. The total output produced at time t, $Y_{t}$, is given by

$$
Y_{t}=K_{t}^{\alpha} G_{t}^{\beta} S_{t}^{1-\alpha-\beta}+L_{t}
$$

where $\alpha, \beta>0$ and $\alpha+\beta<1$. Thus, physical capital and the two types of skills are complements in forming a capital aggregate which substitutes for raw labor in production ${ }^{3}$. Capital-skill complementarity was an idea advanced by Griliches (1969), and Hamermesh (1986) reports on a number of studies that support Griliches' initial result.

\footnotetext{
${ }^{3}$ Our results would hold with alternative production functions (i.e. raw labor could complement the capital aggregate). When raw labor enters the production function as a substitute, however, the dimension of the dynamical system is reduced and the following analysis is considerably simplified.
} 
The aggregate inputs in production are the sum of individual values, and, as will be explained further in the next section, general and job-specific skills and raw labor can all be supplied by a single individual. We consider $S_{t}$ (job-specific skills) and $G_{t}$ (general skills) to be the two components of human capital. Specifically, we define job-specific skills as the portion of an individual's labor supply that is enhanced by the acquisition of knowledge about completing specific tasks. The more tasks an individual can complete, the higher is his level of specific skills. In contrast, general skills is the portion of an individual's labor that allows him to critically analyze and solve problems. The distinction we make is analogous to the distinction labor economists have traditionally made between firm-specific and general skills. In our one-sector model, however, specific skills can be transferred between firms.

Suppose that the world interest rate is stationary at a level $\bar{r}$. Since the small open economy allows unrestricted capital movement, its interest rate is stationary at $\bar{r}$ as well.

$$
r_{t}=\alpha\left[\frac{G_{t}^{\beta} S_{t}^{1-\alpha-\beta}}{K_{t}^{1-\alpha}}\right]=\bar{r} \quad \Rightarrow \quad\left[\frac{G_{t}^{\beta} S_{t}^{1-\alpha-\beta}}{K_{t}^{1-\alpha}}\right] \equiv \Phi>0
$$

Due to the existence of competitive markets, factors of production earn their marginal products. Namely,

$$
\begin{gathered}
w_{t}^{g}=\bar{w} \beta\left(\frac{S_{t}}{G_{t}}\right)^{\frac{1-\alpha-\beta}{1-\alpha}} \\
w_{t}^{s}=\bar{w}(1-\alpha-\beta)\left(\frac{G_{t}}{S_{t}}\right)^{\frac{\beta}{1-\alpha}} \\
w_{t}^{l}=1
\end{gathered}
$$

where $\bar{w} \equiv 1 / \Phi^{\frac{\alpha}{1-\alpha}}$ and where $w_{t}^{g}, w_{t}^{s}$ and $w_{t}^{l}$ respectively denote the wage rates paid to general skills, specific skills and raw labor at time t. 


\subsection{Individuals}

Individuals live for three periods in overlapping generations. The size of the population is normalized to one and there is no population growth. Individuals are endowed with one unit of time and raw labor input in every period. At birth, they are endowed with no amount of general or specific skills. In the first period, individuals divide their time between education and work. Both activities help individuals augment their total labor input. In the second period, they supply all of their labor endowment, including any general and specific skills they have accumulated, to the labor market, and they save. In the third period, individuals consume.

We assume that the time devoted to education, $e_{t-1}^{t-1}$, increases an individual's stock of general skills, $g_{t}^{t-1}$, whereas time devoted to work, $x_{t-1}^{t-1}$, increases his specific skills, $s_{t}^{t-1}$ (We will follow the convention that a subscript denotes the time period in which the variable is observed and the superscript denotes with which generation a variable is associated.) :

$$
g_{t}^{t-1}=\gamma \lambda_{t-1} g\left(e_{t-1}^{t-1}\right)
$$

and,

$$
s_{t}^{t-1}=(1-\gamma) \lambda_{t-1} s\left(x_{t-1}^{t-1}\right)
$$

where $0 \leq \gamma \leq 1, g^{\prime}(),. s^{\prime}()>0,. g^{\prime \prime}(),. s^{\prime \prime}()<$.0 , and where $(1-\gamma) s^{\prime}(1)<\gamma g^{\prime}(0)<\infty$. In the above equations, $\lambda_{t-1}$ denotes the externality that the average level of human capital in period $t-1$ generates by making the amount of time spent working or in school more effective in generating human capital, and, $\gamma$ is a parameter that represents the relative importance of education in the accumulation of human capital.

Let $h_{t}^{t-1}$ denote the individuals' total human capital stock in the second period, which is a function of general skills, $g_{t}^{t-1}$ and the stock of specific skills accumulated through work experience, $s_{t}^{t-1}$ : 


$$
h_{t}^{t-1}=f\left(g_{t}^{t-1}, s_{t}^{t-1}\right)
$$

where $f\left(g_{t}^{t-1}, 0\right), f\left(0, s_{t}^{t-1}\right)>0, \frac{\partial h_{t}^{t-1}}{\partial g_{t}^{t-1}}=f_{1}(),. \frac{\partial h_{t}^{t-1}}{\partial s_{t}^{t-1}}=f_{2}() \geq 0,. \frac{\partial^{2} h_{t}^{t-1}}{\partial\left(g_{t}^{t-1}\right)^{2}}=f_{11}($.$) ,$ $\frac{\partial^{2} h_{t}^{t-1}}{\partial\left(s_{t}^{t-1}\right)^{2}}=f_{22}() \leq 0,. \frac{\partial^{2} h_{t}^{t-1}}{\partial g_{t}^{t-1} \partial s_{t}^{t-1}}=f_{12}()=.\frac{\partial^{2} h_{t}^{t-1}}{\partial s_{t}^{t-1} \partial g_{t}^{t-1}}=f_{21}() \geq$.0 . We assume that the function $f\left(g_{t}^{t-1}, s_{t}^{t-1}\right)$ is homogenous of degree 1 . Thus, we can rewrite equation (6) as

$$
h_{t}^{t-1}=\lambda_{t-1} f\left[\gamma g\left(e_{t}^{t-1}\right),(1-\gamma) s\left(1-e_{t}^{t-1}\right)\right]
$$

We assume that the externality in human capital accumulation in period $t-1, \lambda_{t-1}$, is an increasing concave function of the average human capital stock in that period, $h_{t-1}$ :

$$
\lambda_{t-1}=\lambda\left(h_{t-1}\right) ; \quad \text { where } \quad \lambda^{\prime}\left(h_{t-1}\right) \geq 0, \quad \lambda^{\prime \prime}\left(h_{t-1}\right) \leq 0
$$

Note that since all individuals are identical within a generation, the old do not work, and the young have no human capital, the average level of human capital, $h_{t-1}$, is equal to the level of human capital of a middle-aged worker, $h_{t-1}^{t-2}$. Thus, $\lambda_{t-1}$ represents the older generations' effect on the human capital of the young-an individual's work experience and schooling is more effective in producing human capital if members of the older generation have higher levels of human capital.

Individuals receive utility from consumption in the third period. The utility of an individual of generation $t-1$ is

$$
u^{t-1}=u\left(c_{t+1}^{t-1}\right)
$$

where $u^{\prime}()>0,. u^{\prime \prime}()<$.0 , and, where $c_{t+1}^{t-1}$ denotes the consumption of the individual in the last period. 
Individuals maximize their utility as given by equation (9), subject to $e_{t-1}^{t-1}+x_{t-1}^{t-1} \leq$ 1 and to the following budget constraint:

$$
c_{t+1}^{t-1} \leq(1+\bar{r}) I_{t}^{t-1}=(1+\bar{r})\left[\left(1+(1+\bar{r}) x_{t-1}^{t-1}\right)+w_{t}^{g} g_{t}^{t-1}+w_{t}^{s} s_{t}^{t-1}\right]
$$

Therefore, the optimal amount of time allocated to education by the individual, $e_{t-1}^{t-1}$, satisfies the following first order condition:

$$
\gamma g^{\prime}\left(e_{t-1}^{t-1}\right) w_{t}^{g}-(1-\gamma) s^{\prime}\left(1-e_{t-1}^{t-1}\right) w_{t}^{s}=\frac{1+\bar{r}}{\lambda\left(h_{t-1}\right)}
$$

Equation (11) implies that the optimal amount of time devoted to education by an indiviudal born in period $t-1, e_{t-1}^{t-1}$ is a non-decreasing function of the average parental human capital stock in period $t-1$. Namely,

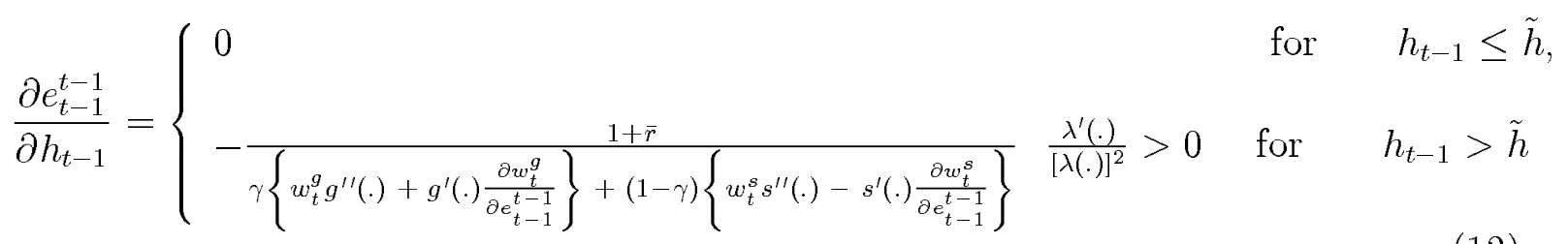

where $\tilde{h}$ is the highest value of the parental human capital stock for which individuals choose no education. Thus,

$$
e_{t-1}^{t-1}= \begin{cases}0 & \text { for } \quad h_{t-1} \leq \tilde{h} \\ e\left(h_{t-1}\right) & \text { for } \quad h_{t-1}>\tilde{h}\end{cases}
$$

and,

$$
\lim _{h_{t-1} \rightarrow \infty} e_{t-1}^{t-1}<1
$$




\section{The Evolution of the Economy}

In this economy, the human capital stock in period $t, h_{t}$, is determined by the human capital stock in the previous period, $h_{t-1}$. Namely,

$h_{t}=\psi\left(h_{t-1}\right)= \begin{cases}\lambda\left(h_{t-1}\right) f[\gamma \tilde{g},(1-\gamma) \tilde{s}] & \text { for } \quad h_{t-1} \leq \tilde{h} \\ \lambda\left(h_{t-1}\right) f\left\{\gamma g\left[e\left(h_{t}^{t-1}\right)\right],(1-\gamma) s\left[1-e\left(h_{t}^{t-1}\right)\right]\right\} & \text { for } \quad h_{t-1}>\tilde{h}\end{cases}$

where $\tilde{g} \equiv g(0), \tilde{s} \equiv s(1)$ and where the initial stock of human capital, $h_{0}$, is historically given. The evolution of the economy can be further characterized by

$\frac{\partial h_{t}}{\partial h_{t-1}}=\psi^{\prime}\left(h_{t-1}\right)= \begin{cases}\lambda^{\prime}\left(h_{t-1}\right) f[\gamma \tilde{g},(1-\gamma) \tilde{s}] \geq 0 & \text { for } \quad h_{t-1} \leq \tilde{h} \\ \lambda^{\prime}\left(h_{t-1}\right) f\left\{\gamma g\left[e\left(h_{t}^{t-1}\right)\right],(1-\gamma) s\left[1-e\left(h_{t}^{t-1}\right)\right]\right\} & \text { for } \quad h_{t-1}>\tilde{h} \\ & +\lambda\left(h_{t-1}\right)\left\{\gamma f_{1}(.) g^{\prime}\left[e\left(h_{t-1}\right)\right]-(1-\gamma) f_{2}(.) s^{\prime}\left[1-e\left(h_{t-1}\right)\right]\right\} \frac{\partial e_{t-1}^{t-1}}{\partial h_{t-1}}\end{cases}$

When $h_{t-1} \leq \tilde{h}$, the human capital stock is increasing in the previous generation's level. When $h_{t-1}>\tilde{h}$, it is not possible to sign $\frac{\partial h_{t}}{\partial h_{t-1}}$ in all cases. For low values of $h_{t-1}$, $e\left(h_{t-1}\right)$ is also low and $\gamma f_{1}(.) g^{\prime}\left[e\left(h_{t-1}\right)\right]>(1-\gamma) f_{2}(.) s^{\prime}\left[1-e\left(h_{t-1}\right)\right]$, and a non-negative slope for $\psi\left(h_{t-1}\right)$ is ensured. However, for sufficiently high values of $h_{t-1}$, it is possible that $\gamma f_{1}(.) g^{\prime}\left[e\left(h_{t-1}\right)\right]<(1-\gamma) f_{2}(.) s^{\prime}\left[1-e\left(h_{t-1}\right)\right]$, and, thus, for some specifications, $\frac{\partial h_{t}}{\partial h_{t-1}}$ may be negative. Nonetheless, we are able to establish

$$
\lim _{h_{t-1} \rightarrow \infty} \psi^{\prime}\left(h_{t-1}\right)=0
$$


In addition,

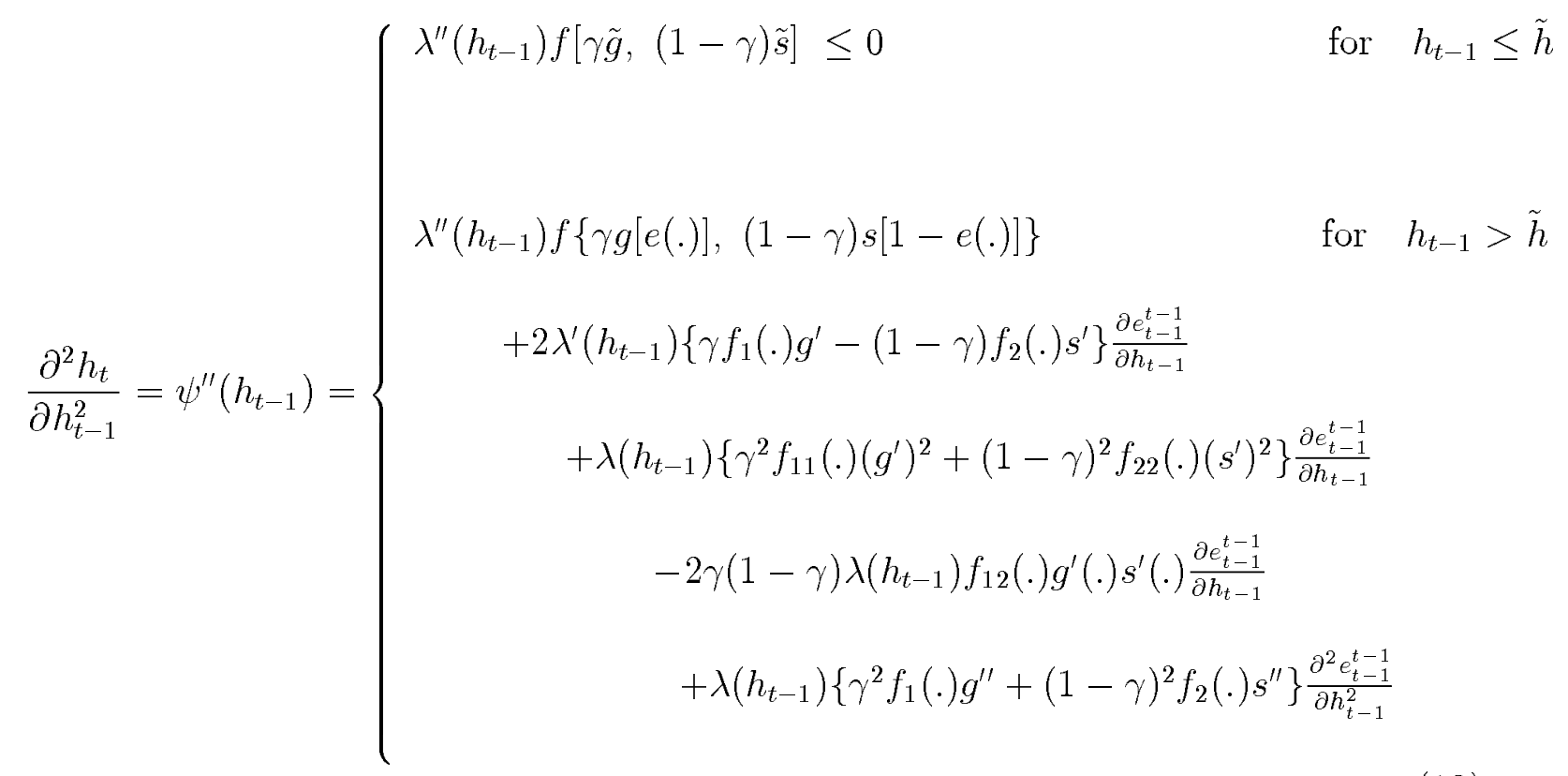

Noting that

$$
\lim _{h_{t-1} \rightarrow \mathbf{0}} \psi^{\prime}\left(h_{t-1}\right)=\lambda^{\prime}\left(h_{t-1}\right) f[\gamma \tilde{g},(1-\gamma) \tilde{s}] \geq 0
$$

and that $\psi^{\prime}(0)$ can be greater than 1, using (17), we are able to establish the existence of at least one steady state. Figure 1 depicts one possible shape for $\psi\left(h_{t-1}\right)$ when there is one steady state level of $h_{t}$.

It is also possible, however, that multiple steady states exist. We demonstrate the possible existence of multiple steady states by example. In particular, when $\psi(\tilde{h})<\tilde{h}$, a steady state with no education exists. An examination of equation (11) reveals that there exists parameter values such that the opportunity costs of education are sufficiently high so that individuals allocate no time to education. For example, a sufficiently high value of the world interest rate, $\bar{r}$, and/or a low value of $\lambda($.$) evaluated at e_{t-1}^{t-1}=0$ would 
satisfy this condition. This guarantees the existence of a steady state with no education (i.e. $\psi(\tilde{h})<\tilde{h})$. Moreover,

$$
\lim _{h_{t-1} \rightarrow \tilde{h}^{+}} \psi^{\prime}\left(h_{t-1}\right)=\left\{\begin{array}{l}
\lambda^{\prime}(\tilde{h}) f[\gamma \tilde{g},(1-\gamma) \tilde{s}] \\
\quad+\lambda(\tilde{h})\left\{\gamma f_{1}(.) g^{\prime}(0)-(1-\gamma) f_{2}(.) s^{\prime}(1)\right\} \frac{\partial e_{t-1}^{t-1}}{\partial h_{t-1}}
\end{array}\right.
$$

Thus, (20) implies that the slope of the function $\psi\left(h_{t-1}\right)$ can be large enough to guarantee the existence of a steady state with education, provided that $\gamma f_{1}(.) g^{\prime}(0)-(1-$ $\gamma) f_{2}(.) s^{\prime}(1)$ is sufficiently large. The term $\gamma f_{1}(.) g^{\prime}(0)-(1-\gamma) f_{2}(.) s^{\prime}(1)$ identifies the net marginal effect of an increase in education when individuals devote no time to it. Thus, if it is sufficiently high, a steady state with a positive amount of time devoted to education exists. The evolution of the human capital level, $h_{t}$, under these conditions is depicted in Figure 2.

In this economy, the evolution of the human capital stock, $\left\{h_{t}\right\}_{t=0}^{\infty}$, in turn determines the evolution of the amount of time allocated to education, $\left\{e_{t}\right\}_{t=0}^{\infty}$, the stock of general skills, $\left\{G_{t}\right\}_{t=0}^{\infty}$, the stock of specific skills, $\left\{S_{t}\right\}_{t=0}^{\infty}$, the net amount of raw labor input, $\left\{L_{t}\right\}_{t=0}^{\infty}$, and per capita income, $\left\{y_{t}\right\}_{t=0}^{\infty}$.

\section{Externalities}

In our model, increases in the stock of skills enhance the accumulation of future skills. We have demonstrated that, in response to increases in the average skill level, individuals choose to allocate a positive and increasing amount of time to education once the human capital stock is above the threshold level, $\tilde{h}$. Thus, when the human capital stock is monotonically increasing as an economy develops, the total stock of general skills, $G_{t}$, increases and the stock of specific skills accumulated through work experience, $S_{t}$, declines. 
Because both general and specific skills affect the externality that the average level of human capital generates and the individual's private reward differs from the social reward, a socially inefficient level of education will result. In particular, individuals' suboptimal choice of education will generate slower growth during the transition to the steady state. However, contrary to the standard result that individuals do not choose enough education, our model, which includes job-specific skills as part of human capital, demonstrates that the nature of the inefficiency can change as an economy grows and accumulates more human capital. In fact it is trivial to show that, when the marginal effect of time allocated to education in producing general skills is greater than that of time allocated to work in producing specific skills (i.e. $\left.\gamma f_{1}(.) g^{\prime}()>.(1-\gamma) f_{2}(.) s^{\prime}().\right)$, more education leads to a higher positive externality in human capital accumulation, faster accumulation of the factors of production and a higher economic growth rate ${ }^{4}$. During these periods, individuals choose to allocate too little time time to education since they do not take into account the positive effect increases in their education would have on the human capital of the next generation. In other words, at low levels of development, the effectiveness of education in producing general skills is not high enough to produce a private return to education that is as high as the social return to education ${ }^{5}$.

Nevertheless, as the stock of human capital increases, individuals choose to devote more time to education. In fact, in later stages of development, if the marginal effect of time allocated to education in producing general skills becomes less than that of time allocated to work in producing specific skills (i.e. $\gamma f_{1}(.) g^{\prime}()<.(1-\gamma) f_{2}(.) s^{\prime}($.$) ), the optimal$ amount of time that individuals devote to education creates a negative social externalityfactor accumulation would be faster at lower levels of education. This situation will occur if the marginal private reward for investing in education, $w_{t}^{g} \gamma \lambda\left(h_{t-1}\right) g^{\prime}\left(e_{t-1}^{t-1}\right)$, is "too high" and does not provide the appropriate incentive to invest in the socially optimal

\footnotetext{
${ }^{4}$ Note that $\lambda\left(h_{t-1}\right)$ reaches a maximum when $\gamma f_{1}(.) g^{\prime}()=.(1-\gamma) f_{2}(.) s^{\prime}($.$) .$

${ }^{5}$ The distinction between the return to education and the return to general skills is an important one. At low levels of development, the wage return to general skills would be high, but education is not very effective in producing general skills, and thus, the private return to education would be lower.
} 
level of education. Of course, the likelihood that this situation will occur will be greater for higher values of $\beta$ which, in our formulation, determines the share of general skills in total income.

Thus, when there are multiple steady states in this economy, it is possible that none are efficient. At the low-income steady state, individuals invest too little in education, and at the upper steady state, individuals invest too much. Per capita income at the lower steady state can be increased by raising investment in education and per capita income in the upper steady state can be increased by lowering investment in education (and increasing investment in specific skills). Even when there is only one steady state, the dichotomy between private and social returns creates inefficiencies along the transition to it. Growth is first slowed by under-investment in education which may, in later stages of development, turn into over-investment in education. It is important to note that the key feature of the model that produces the inefficiencies is that general and specific skills are combined in different ways in production and in the formation of the human capital.

In sum, including work experience as a valid method of accumulating human capital and valuing the job-specific skills that result from it can have important implications for the dynamic behavior of the economy. To emphasize this point, we could consider a subset of our model that puts little emphasis on the role that work experience plays (For example, this can be done by setting $\gamma$ in equation (7) very large). In this subcase, the effect of work experience is minimized and an overeducated steady state cannot be achieved. Thus, our model resembles the more traditional models in which education is the primary means of accumulating human capital. Because the inclusion of work experience leads to such dramatically different results, we are led to conclude that the existence of alternative means of accumulating human capital, such as through work experience, is a possibility to be carefully considered. 


\section{Conclusion}

We have attempted a look inside the black box called aggregate human capital. In doing so, we have shown that the complex manner in which individuals accumulate human capital and the way in which individuals are rewarded for accumulating human capital of different types can have important implications for the evolution of the economy. Our model demonstrates that in countries with a large human capital stock, individuals may obtain more than the socially optimal level of education. At the same time, a less developed economy with the same production technology can be under-educated. Thus, increased time devoted to education can lead to either a positive or negative externality. The possible presence of multiple equilibria adds an interesting twist to the usual story-it is possible that none of the equilibria generated by our model are efficient, but they are inefficient for different reasons. Low-income equilibria are characterized by not enough education and high-income equilibria are characterized by too much education.

The key mechanism of our model is that the different types of skill determine the effectiveness of investing in education and work experience in a different manner than they determine wages. Because there is a tradeoff in accumulating general versus job-specific skills, the over-accumulation of one factor causes the under-accumulation of the other. Thus, including work experience as a valid method of accumulating human capital can have important implications for the dynamic behavior and efficiency of the economy. Given the micro-level evidence for the role that experience plays in determining an individual's human capital, we believe this to be an important and justified inclusion in our analysis.

Our conclusions are important for policymakers because they suggest that education is not a panacea for slow growing economies. Optimal policies will have goals for increases in educational attainment that evolve with the economy. More generally, our results indicate that a thorough macroeconomic investigation of all of the channels of human capital accumulation is necessary to effectively formulate and implement the 
most successful policies. This is a fruitful area for further research. 


\section{References}

Azariadis, C. and A. Drazen, 1990, "Threshold Externalities in Economic Development", Quarterly Journal of Economics, 105, 501-26.

Barro, R. J., 1991, "Economic Growth in a Cross Section of Countries", Quarterly Journal of Economics, 106, 407-444.

Becker, G. S., 1993, Human Capital: A Theoretical and Empirical Analysis, with Special Reference to Education, (The University of Chicago Press, Chicago).

Benhabib, J. and M. M. Spiegel, 1994, "The Role of Human Capital in Economic Development: Evidence from aggregate cross-country Data", Journal of Monetary Economics, 34, 143-173.

Coleman, J. S. et al., 1966, "Equality of Educational Opportunity", (U.S. G.P.O., Washington, D.C.).

Fershtman, C., K.M. Murphy, and Y. Weiss, 1996, "Social Status, Education and Growth", Journal of Political Economy, 104(1), February, 108-132.

Galor, O. and D. Tsiddon, 1996, "The Distribution of Human Capital and Economic Growth", Journal of Economic Growth, forthcoming.

Griliches, Z., 1969, "Capital-Skill Complementarity", Review of Economics and Statistics, 51(4), November, 465-68.

Hamermesh, D. S., 1986, "The Demand for Labor in the Long Run", in Handbook of Labor Economics, Vol. I, edited by O. Ashenfelter and R. Layard, (New York: North Holland), 429-71.

Iyigun, M. F. and A. L. Owen, 1995, "The Accumulation of Human Capital: Alternative Methods and Why They Matter", mimeo.

Lucas, R. E., 1993, "Making a Miracle", Econometrica, Vol. 61, No:2, March, 251-72.

Mankiw, N. G., D. Romer and D. N. Weil, 1992, "A Contribution to the Empirics of Economic Growth", Quarterly Journal of Economics, 107, 407-437. 
Mincer, J., 1993, Studies in Human Capital: Collected Essays of Jacob Mincer, Vol. 1, (Brookfield, VT: Edward Elgar Publishing Company).

Mincer, J., 1996, "Economic Development, Growth of Human Capital and the Dynamics of the Wage Structure", Journal of Economic Growth, 1(1), March, 29-48.

Pritchett, L., 1995, "Where has all the education gone?", mimeo.

Romer, P. M., 1990, "Endogenous Technological Change", Journal of Political Economy, 98(5), October, 571-602.

Stokey, N. L., 1988, "Learning by Doing and the Introduction of New Goods", Journal of Political Economy, XCVI, 701-717. 


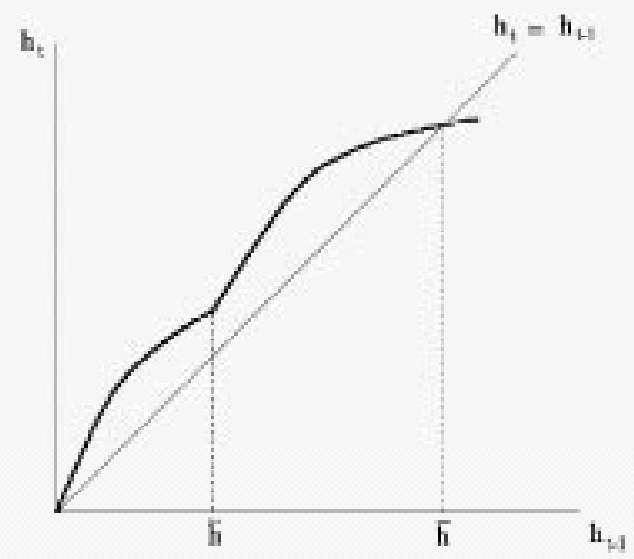

Figure 1:

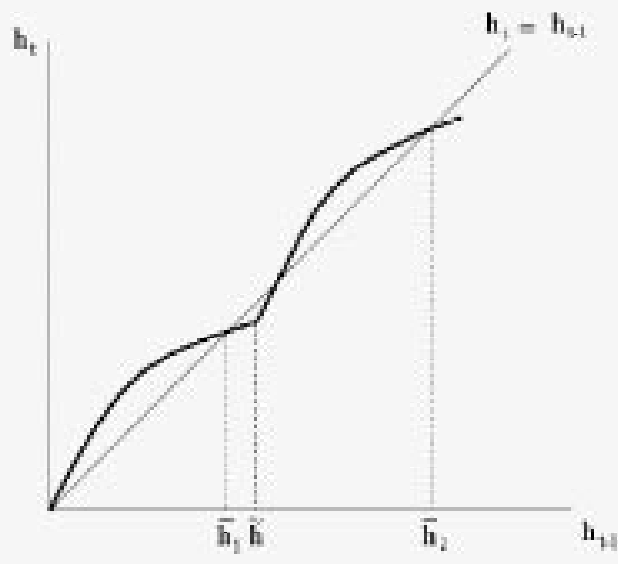

Figure 2: 